\title{
The Future Of Marketing
}

Mok Kim Man, (E-mail: mkimman@yahoo.com), Universiti Malaysia Sabah, Malaysia.

Jainurin Justine, Universiti Malaysia Sabah, Malaysia.

\begin{abstract}
This paper aims to examine the future of marketing as it relates to one of the four categories of generalizations identified by Sheth and Sisodia (1999) in their paper, "Revisiting marketing's lawlike generalizations." The category to be discussed in depth will be location-centric concepts. As examples of application, case studies from a developing country, Malaysia will be featured and analysed.

The paper is organised in the following structure. Firstly, the essay will provide a background of the development of location-centric marketing concepts, particularly in the area of marketing or distribution channels. Secondly, the essay will provide a background of the major force affecting location-centric marketing concepts, namely the Internet, particularly in the context of electronic commerce. Thirdly, the essay will examine the impact of the Internet on existing location-centric marketing concepts. In this section, the impact of electronic commerce on marketing or distribution channels will be the primary area to be discussed. Fourthly, the essay will present a couple of case studies of such an impact in a developing country, Malaysia. Finally, the essay will conclude with the lessons that can be learnt from the case studies. The conclusion will explore if new constructs with regards to marketing or distribution channels are created or old ones are altered due to the impact of electronic commerce.
\end{abstract}

\section{LOCATION-CENTRIC MARKETING CONCEPTS}

A

ccording to Sheth and Sisodia (1999: 72) the basic framework of "the marketing function was that of physical separation between sellers and buyers". Consistent with the marketing idea that products should be a solution to the problems of buyers, the marketing function is utilised as a product or service to solve the central problem of bringing the product and services of sellers to buyers. Therefore, the marketing function's basic framework stated by Sheth and Sisodia above forms part of this central marketing problem!

The solution to the central problem in marketing is the development and management of marketing or distribution channels (both terms will be used interchangeably throughout this essay). The distribution channel closes the gap between sellers and buyers or producers and users. The importance of marketing channels is further crystallised by Kotler (2000: 490) who wrote, "marketing-channel decisions are among the most critical decisions facing management" and that the choices of the marketing channel "intimately affect all the other marketing decisions." In addition, "distribution channels have been viewed as a strategic asset and channel design has been recognized as a key to successful competition" (Anderson, Day and Rangan, 1997 in Gallaugher 2002).

Despite the importance of other location-centric marketing concepts such as retail gravitation and mediadriven advertising and promotion, this essay will focus mainly on distribution channels. Such a focus is based on the reasons that (1) marketing or distribution channels have strategic values and (2) the impact of the Internet will encompass this particular concept more than the others.

\section{Marketing or distribution channels}

The basic building block of location-centric concepts in marketing is the marketing or distribution channel. An early definition of the distribution channel is "a structural arrangement whereby sellers (or their middlemen representatives) search for customers prospects with whom to communicate and to whom sales can be ultimately 
made, and whereby buyers, in turn, search for sellers carrying the assortments desired from whom purchases ultimately can be made" (Revzan, 1961 in Mallen, 1967: 4). This definition still holds today as seen in a more recent definition of marketing or distribution channel as "the structure formed by interdependent partners participating in the process of making goods or services available for consumption or use by consumers or industrial users" (Lambin, 2000: 512). It is clear that the primary role of a marketing or distribution channel is to act as a structure that moves goods and services from sellers and producers to buyers and users.

\section{Development of Marketing or Distribution Channels}

The father of channel structure theory is Professor Wroe Alderson of Wharton School, University of Pennsylvania, USA. Alderson's sorting theory is considered to be the foundation of the channel structure selection and design (Mallen, 1967: 33). Alderson explained that the development of marketing channels resulted from an evolution process starting with the adoption of exchange by the producers, the individuals or families in primitive societies as means of acquiring goods, progressing through the adoption of exchange in a central location, for example, a village market by the producers and finishing with the introduction of a dealer, who engaged in direct exchange with the producers at the central location (1954, in Mallen, 1967: 35). Alderson stated that the introduction of the dealer as an intermediary added the "possession utility" to the "time and place utility" already brought about by the adoption of a central location for exchange (1954, in Mallen, 1967: 36). As a result, he stated that the introduction of the intermediaries, the dealer, reduced the numbers of direct exchange and increases efficiency of exchange (Alderson, 1954, in Mallen, 1967: 36).

Further, Alderson (1954, in Mallen, 1967: 38) added that problems due to time and space distance and discrepancy of assortments between producers and consumers further developed and widened the role of marketing channel as the bridge or solution. Marketing channels, according to Alderson (1954, in Mallen, 1967: 38-39), resolved the two problems through adjustments from four "sorting" processes as follows:

- $\quad$ Sorting Out: "Breaking down of heterogeneous supply into separate stocks which are relatively homogeneous"

- Accumulation: "Bringing similar homogeneous supply into larger homogeneous stocks"

- Allocation: "Breaking larger homogeneous supply into smaller and smaller lots"

- Assorting: "Building up an assortment of items for use in association with each other"

These processes are still applicable in distribution channels today. Additional functions have been added and will be discussed in section 2.3 below.

Alderson (1954, in Mallen, 1967: 39) also stated that the development of marketing channels was further enhanced by the routinisation of exchange transactions by intermediaries and the use of the channels as a medium for customers or buyers to search for products and services.

These early concepts are still valid today as observed by Lambin (2000: 513), who stated that the rationale for marketing channels are made up of contractual efficiency, economies of scale, reduction of functional discrepancies, better assortment and better service. Therefore, we can say that the reasons of past years are still valid today as they were previously.

\section{Key Functions of Marketing or Distribution Channels}

Let us now look at the key functions of marketing channels in detail. In addition to the four "assorting" processes discussed above, according to Kotler (2000: 491), a marketing channel's tasks are as follows:

- Gathering information about potential and current customers, competitors and other actors and forces in the marketing environment

- $\quad$ Developing and disseminating persuasive communication to stimulate purchasing

- $\quad$ Reaching agreement on price and other terms so that transfer of ownership or possession can be effected 
- $\quad$ Placing orders with manufacturers

- $\quad$ Acquiring funds to finance inventories at different levels in the marketing channels

- $\quad$ Assuming risks connected with carrying out channel work

- $\quad$ Providing the successive storage and movement of physical products

- $\quad$ Providing for buyers' payment of their bills through banks and other financial institutions

- $\quad$ Overseeing actual transfer of ownership from one organization or person to another

In addition to the above, Lambin (2000: 512) identified the following tasks for marketing channels:

- Making goods available in a quantity or volume adapted to consumers' purchasing habits

- $\quad$ Establishing personalised relationships with customers who are numerous and remote

\section{Levels in Marketing or Distribution Channels}

Marketing channels are generally classified based on the number of links or intermediaries between the seller or producer and the buyer or consumer. The earliest classification of marketing channels, according to Revzan (1961 in Mallen, 1967: 6), divided channels into (1) direct channels (single link or direct contact between the seller or producer and the buyer or consumer), (2) indirect channels (multiple links or numerous intermediaries between seller or producer and the buyer or consumer) and (3) semi-direct channels (in between direct and indirect channels with one or two intermediaries between seller or producer and the buyer or consumer). Today's classification still follows the same notion. For example, Kotler (2000: 492-493) classified the length of channels based on the number of intermediaries existing in the channels. According to Kotler (2000: 492-493), channels are categorized into zero-level channels, one-level channels, two-level channels, three-level channels, so on and so forth, based on the number of intermediaries between the seller or producer and the buyer or consumer. A graphical presentation of the categorization is shown as Figure 1 in the Appendix.

\section{Selection of Distribution Channels}

A key part to understanding distribution channels is to understand how the design and selection of a channel is done. As stated earlier, the choice of distribution channels has far reaching implication on all other marketing decisions.

Earlier on, the factors affecting the selection of the distribution channel structure were the "underlying conditions of production", "the commodity characteristics" and "factors that explain the importance of wholesale middlemen" (Revzan, 1961 in Mallen, 1967: 9). Presently, however, selection of channel structure is based on market factors, product characteristics and company variables (Lambin, 2002, p.521). Based on this, we conclude that out of the three early factors, the directly relevant one today is the product characteristics. However, we can consider market structure and company variables as part of the underlying conditions for production. Based on the analysis later, product characteristics will turn out to be the key factor in the impact of the electronic commerce on distribution channels.

\section{THE INTERNET AND ELECTRONIC COMMERCE}

Without a doubt, the Internet is probably the most important technological advancement in the past two or three decades. The rapid development in information technology and communication created vast opportunities for companies to reconstruct and improve internal and external business processes, including those related to marketing.

\section{The Internet}

According to Kalakota and Whinston (1997: 37), the Internet is either "a network of networks, or an 'internetwork', linking computers worldwide," or "a collection of computers networks composed of computers that use dissimilar operating systems and contain a variety of contents". It is said that the Internet started in the 1960's in the USA when the first few networks were linked up or networked for military and academic reasons. Only in the past 
decade or two, the use of the network of networks has moved into the commercial segments, the reasons being (1) the ubiquity of personal computers and (2) the advancements in computer software and hardware as well as in telecommunication technology.

The Internet comprises a number of applications or tools such as electronic mails, newsgroups, file transfers, and the World Wide Web or the Web as well as a myriad of computing and communication equipments. The Web is "a collection of distributed documents referred to as "pages" located on computers (or servers) all over the world" (Kalakota and Whinston, 1997: 66). The use of a common computer language, the hypertext markup language (HTML) and a common communication protocol, the hypertext transfer protocol (HTTP) enables networks to link with each other. Chaffey (2002: 76) stated that the Web enables an easy exchange of information between business and consumers due to the use of standard tools. follows:

A variety of reasons for the success of the Web are proposed by Kalakota and Whinston (1997: 69) as

$\begin{array}{ll}- & \text { Ease of navigation and use } \\ - & \text { Ease of publishing content } \\ - & \text { New distribution models } \\ - & \text { Enabling a network-centric computing paradigm } \\ & \text { Enabling new intra-business applications }\end{array}$

The third reason has strong ramifications to marketing. So, lets discuss this point further. According to Kalakota and Whinston (1997: 71), the Web allows any type of good or services to be purchased through it in a faster and more convenient way, citing examples such as banking services and software distribution. The effect of such changes on traditional distribution or marketing channels will be discussed in Section 4.0 below.

\section{Electronic Commerce}

On very broad terms, we can say that electronic commerce is simply commerce or business conducted over electronic means. As such, we can trace the development of electronic commerce back to the days of Electronic Data Interchange (EDI's) in the 1970's. However, as a result of the opening up and wider use of the Internet, electronic commerce has expanded rapidly in the past 10 to 15 years. Based on Forrester Research (2000 in Chaffey, 2002: 13), worldwide electronic commerce is expected to grow about ten-fold from 657.0 billion United States Dollar (USD) in 2000 to 6,789.3 billion USD in 2004. Table 2 in the Appendix shows the worldwide electronic commerce growth from 2000 to 2004. Generally, a majority of the electronic commerce sales is from company to company sales, or business to business or "B2B" commerce as it is known in the electronic commerce parlance. Sales from company to consumer or business to consumer or "B2B" commerce are much lower.

Kalakota and Whinston (1997: 71) defined electronic commerce from the following four perspectives:

- Communication perspective: Electronic commerce is the delivery of information, products and/or services, or payments via telephone lines, computer networks, or any other electronic means.

- Business process perspective: Electronic commerce is the application of technology toward the automation of business transactions and workflows.

- $\quad$ Service perspective: Electronic commerce is a tool that addresses the desires of firms, consumers, and management to cut service costs while improving the quality and the speed of service delivery.

- $\quad$ Online perspective: Electronic commerce provides the capability of buying and selling products and information on the Internet and other online services.

Various writers and researches have espoused the benefits of the electronic commerce. Hoffman, Novak and Chatterjee (1995: 4-6), for example, identified the following: 


\section{Benefits to Consumers}

- $\quad$ Access to greater amounts of dynamic information to support queries for consumer decision-making.

- $\quad$ Potential of wider availability of hard-to-find products and wider selection of items due to the width and efficiency of the channel.

- $\quad$ For industrial consumers, reduced costs to buyers from increased competition in procurement as more suppliers are able to compete in an electronically open marketplace.

\section{Benefits to Sellers}

- The use of the Web as a distribution channel, including offering certain classes of providers participation in a market in which distribution costs or cost-of-sales shrink to zero. For example, digital products can be delivered immediately.

- $\quad$ Transfer of more of the selling function to the customer such finding the right product and filling orders.

- Conducive environment to developing customer relationships as the Web cover much more than the traditional media.

- $\quad$ Available 24 hours a day and anywhere in the world.

- $\quad$ Opportunity for competition on the "specialty" axis instead of the price axis, as from a marketing perspective, it is rarely desirable to compete solely on the basis of price.

- $\quad$ For industrial sellers, the operational benefits are reduced errors, time, and overhead costs in information processing; reduced costs to suppliers by electronically accessing on-line databases of bid opportunities, online abilities to submit bids, and online review of awards. follows:

Hoffman, Novak and Chatterjee (1995: 11-12) also identified some barriers to electronic commerce as

- $\quad$ Ease of access, namely, the "bandwidth" problem, ease of finding a service provider, and the diffusion of the computer hardware/software/modem bundle into the home.

- $\quad$ Ease of use includes issues such as the user-friendliness of the software, ease of software installation, and the like.

- $\quad$ The security of financial information transmitted over the Internet.

- $\quad$ Web measurement problem as firms are unsure of the number of people on the Net and how many people use the Web and this uncertainty makes investment decisions difficult.

Despite the problems faced in commercialisation of the Web, many companies went ahead to implement electronic commerce strategies and initiatives in the mid to late 1990's as seen in the Internet boom during this period. Of course, history showed that a large number of these ventures did not succeed as seen by the subsequent Internet bubble burst in 2000 .

\section{IMPACT OF ELECTRONIC COMMERCE ON DISTRIBUTION OR MARKETING CHANNELS}

Based on the benefits of the Internet and electronic commerce, we have seen several impacts on the traditional distribution or marketing channels. Three of these impacts will be discussed further below.

\section{Disintermediation of Channels}

The first impact arises from the Internet enabling new distribution models. For example, in the airline industry, passengers are able to purchase tickets through the websites of the airlines. In doing so, the traditional intermediary, the travel agents, is by-passed. Customers and sellers interact directly. This problem is known as disintermediation or as stated by Chaffey (2002: 37) "cutting out the middleman".

Gallaugher (2002) defined disintermediation as "an elimination of one or more organizations from the distribution channel". He cited that "the rise of overnight delivery services and the ubiquity of the Internet have 
offered increased opportunities for firms that originate products and services to sell directly to consumers" (Gallaugher, 2002).

Although the ramifications to traditional can be significant, Gallaugher (2002) argued that due to the removal of the intermediaries, there will be value gaps in the channel in the form of less tangible assets like market knowledge in matters such as distribution, brand and market coverage. He cited examples of Sunburst Farms and Liberty Financial Cos., whose products, FlowerNet and WebSaver" respectively, which failed to take off as they clashed with the traditional channels of distribution, namely, floral shops and financial product agents (Gallaugher, 2002). Other more examples are the failures of General Motors and Levi's in selling automobiles and apparels through the company's website.

\section{Reintermediation of Channels}

The second impact also arises from the Internet enabling new distribution models. However, in this case, additional intermediary is added on to the distribution or marketing channels. For example, in the case of "Amazon.com", buyers are able to purchase books through the website. In order to reach their customers, the sellers, namely the book publishers, add another intermediary to the traditional channel. The sellers may also replace the traditional intermediary, by a new one. In "Amazon.com's" case, the website is a replacement for physical bookstores. This problem is known as reintermediation.

Wigand (1997: 4) defined reintermediation as the replacement of intermediaries between manufacturer or supplier and customer or buyer by an electronic maker or a by value networks. According to Chaffey (2002: 39), the new intermediaries can provide services such as supplier search or product evaluation. Wigand (1997: 7-8) attributed the potential reduction of transaction costs through use of information technology to firms' desire to shift to an alternative intermediary on the Web. He further the same reason is applicable in the case of disintermediation (Wigand 1997: 9).

In addition to "Amazon.com", some other examples where reintermediation occurs are "eBay.com", where sellers can move from traditional auction houses such as Sotheby's and Christie's, and "CDNOW.com", where music publishers move from traditional record shops or outlets.

\section{New "Medium" in Direct Marketing}

The third impact also arises from the Internet enabling new distribution models. However, in this case, the impact is in the context of direct marketing. In the traditional marketing or distribution channel, the lowest level of classification based on channel length is the zero-level channel (refer to Section 2.3 and Figure 1 in the Appendix). Zero-level channels are also known as direct marketing, where the seller or manufacturer deals, markets or sells directly to the buyers or customers. Prior to the wide usage of the Internet, there were three main mediums of direct marketing, namely person-to-person, mailing and telemarketing. Nowadays, firms are able to use the Internet as a new medium to reach their customers. The use of websites where sales and purchases are transacted and the use of electronic mail where sales and purchases are solicited are two good examples of firms moving the marketplace to the marketspace. As we are aware, the Internet extent can be far reaching. Therefore, the possibilities for firms of increasing sales and purchases through this new medium of direct marketing can be endless!

\section{IMPACT OF THE ELECTRONIC COMMERCE ON DISTRIBUTION CHANNELS IN MALAYSIA}

Like many other countries, Malaysia is jumping on the bandwagon on the information superhighway. The Internet usage in the country has grown from 42,000 in 1995 to about 8.2 million in 2003 (Malaysian Communications and Multimedia Commission 2003). Table 1 in the Appendix shows the annual numbers of Internet users from 1995 to 2003. Based on the data, in 2003, Internet users are about 33\% out of a total population of 25 million people. This has increased enormously from 1995, when the Internet users' rate was less than $1 \%$. 
However, despite the increasing number of Internet users, electronic commerce has not caught on big time, particularly in business-to-consumer sector. Ang (2000) stated that most Malaysian retailers were not going to the electronic way due to payments issues and fraud concerns, resulting in the Web being used primarily for advertising and promotion purposes only. As a matter of fact, security was the chief barrier to electronic commerce cited by businesses in a survey done in 1999 in the Klang Valley, Malaysia's economic centre and the location of national capital (Abd. Mukti 2000). To resolve the payment problems, some firms resorted to off-line payment methods (Ang 2000).

Despite the problems, a number of local companies are taking on the Internet with vigour. Two oft-cited examples are the bank, Maybank and the airline, AirAsia. The next two sub-sections will feature the electronic commerce initiatives undertaken by both organisations and how these initiatives relate to the distribution or marketing channels.

(Remarks: Unless noted, all company information came from the companies' respective websites, namely for Maybank at http://www.maybank2u.com.my/ and for AirAsia at http://www.airasia.com/)

\section{Case Study No. 1: Maybank}

\section{Company Background}

Maybank is Malaysia's largest banking group based on asset values. The bank also has the largest market share in Malaysia for commercial banking business. Among local banks, the bank has the most number of branches throughout the country. Maybank also has a number of overseas branches and subsidiaries.

Maybank is the market leader in terms of adopting computer and communication based technologies. The bank is the first Malaysian bank to embark on computerisation programme, implement use of Automated Teller Machines or ATM's, introduce phone banking, implement electronic terminal banking and introduce Internet banking. billion MYR.

In 2003, the bank posted a pre-tax profit of 2.62 billion Malaysian Ringgit (MYR) and revenue of 10.02

\section{Use of Electronic Commerce and its Impact}

In June 2000, Maybank became the first domestic bank to launch Internet banking services. In April 2003, the bank launched Internet banking kiosks, by which it provided terminals at its branches to enable customers to undertake their Internet banking transactions. By the middle of 2003, the number of Maybank's Internet users has increased to more than 1 million with the number transactions in excess of 2 million. The bank expects 1.2 million or 20 per cent of its 6 million account holders will become Internet banking users by the end of 2003 .

On a related development, Maybank began implementation of an Internet-based e-Procurement solution that will link both the bank and its suppliers and vendors in November 2002. The bank expects the initiative to increase operational efficiency.

The main use of the Internet banking services is for payment of bills and transfer of funds. For bill payments, Maybank currently has 325 organisations, which are able to accept payments through the bank's Internet banking services. The total average transaction amounts to 500 million MYR monthly. By the end of 2003, the bank expects the number of organisations to grow to 400 and the amount of monthly transaction to increase to 700 million MYR.

The bank reported that the number of transactions through Internet banking in financial year 2002/2003 rose by $64 \%$ over the previous financial year. However, no breakdown is available for the share of Internet banking in the fees from its transactional banking services, which grew by $10 \%$ to 665 million MYR in financial year 2002/2003 from 607 million MYR in financial year 2001/2002. 
Although there are no concrete measurements to evaluate the success of Maybank's initiatives, we can surmise that Maybank is heading in the right direction based on the increasing number of users and organisations involved as well as the value of transactions. The bank did not remove any of its intermediaries in the process of implementing its Internet initiatives. Maybank basically extended its service channel from its physical branches and telephone banking to the Internet.

Benefits to consumers are obvious. The Internet banking provides convenience to users. For example, the average person has to pay a number of bills every month to different organisations. With Internet banking, the person can make the payments on-line and without the hassle of physically going to places where these payments are to be made in person. Imagine having to go to the telephone company, the Internet provider company, the water supply company, the electricity supply company, so on and so forth every month to settle your bills. A number of other local banks and foreign-owned banks have also introduced Internet banking to their customers.

If awards for its Internet initiatives are to be used as a gauge of success, Maybank can claim some success. In 2000, the bank won the award for the Electronic commerce Site of the Year from the computer industry association of Malaysia. In 2001 and 2002, the Global Finance awarded Maybank with the awards as the best Internet bank in Malaysia.

\section{Case Study No. 2: AirAsia}

\section{Company Background}

AirAsia is a low cost or budget airline, which serves most major destinations within Malaysia. The airline also plans to expand its services to neighbouring countries in Southeast Asia. The airline was transformed from a conventional full service one in January 2002, after it was acquired by a new set of owners at the end of the previous year. Following the transformation, the airline has been operating based on the models used of Southwest and JetBlue airlines in the USA and easyJet and Ryanair in Europe. The premise of the models used is to provide very limited services, while offering lower fares to passengers.

The key of the strategy of low cost airlines is to reduce costs while at the same time offering low prices to passengers (Boone, 2002). As such, AirAsia does a lot to reduce its operating costs so much so that the Chief Executive Officer considers the enemy of the airline is not other airlines but cost. One such way to reduce cost is to adopt Internet reservation systems, which AirAsia has done.

In 2003, AirAsia reported profits and revenue of 20 million MYR and 335 million MYR respectively for financial year 2002/2003.

\section{Use of Electronic Commerce and its Impact}

In May 2002, 5 months after it changed its operating model, AirAsia implemented an Internet reservation system, which allowed on-line payment. AirAsia made a bold move to introduce a website that enabled payment by users. There is only a small number of Malaysian businesses having electronic commerce websites and even fewer having websites which enabled on-line payment. In comparison, AirAsia's major competitor, Malaysia Airlines todate has not done so, providing only arrival and departure schedules on-line.

Two months earlier in April 2002, AirAsia had (1) introduced ticket-less ticketing system, by which passengers are given a booking number and required to provide the same and a photo identification at the check in counter, and (2) enabled payment of air tickets using credit cards through telephone via its call centre. Previously, the call centre only handled enquiries and bookings. In addition to its call centre and Internet reservations systems, AirAsia also uses reservations and sales offices and travel agents as distribution channels for its tickets. Sales through travel agents make up a bout a quarter of the total sales (Devesahayam 2003). The airline has only 13 preferred travel agents throughout the country. Based on the very select few preferred travel agents, we can say that AirAsia has limited use of travel agents as third party intermediaries from distribution channel point of view. However, AirAsia 
has not abandoned the travel agents as it has introduced a B2B initiative to its preferred travel agents, who are able to book an inventory of seats and to make immediate payment to the airline vide a virtual credit card.

In August 2003, AirAsia went a step further with a new electronic commerce initiative, when it introduced reservation and payment of tickets via Short Messaging System (SMS) through mobile phone services. The airline claimed that the initiative was the first of its kind in the world.

In early 2003, AirAsia announced the final results of its operations from April 2001 to June 2002 and preliminary results of operations from July to December 2002 and among the key achievements were as follows:

- $\quad$ The airline managed to turnaround a net loss of 19.1 million MYR from the first eight months to a net profit of 19.4 million MYR in the last seven months, the period under the new management. Net income from July to December 2002 amounted to 11.8 million MYR.

- $\quad$ Revenue increased from 167.8 million MYR in financial year 2000/2001 to 222.3 million MYR in financial year 2001/2002. Revenue for the period from July to December 2002 was 114 million MYR.

- Passenger load factor increased from 67\% in financial year 2000/2001 to 70\% in financial year 2001/2002.

- Internet reservations grew from 0\% in financial year 2000/2001 to 25\% in financial year 2001/2002.

- Number of aircrafts grew from two to six, while number of destinations grew from four to ten.

Based on the above, we can conclude that AirAsia had achieved a creditable turnaround to become a profitmaking airline from a loss-making one. Increases in revenue and profits have been tremendous although direct impact of the Internet reservation system was less certain. However, the airline recently reported that since launching the Internet reservation system, it had obtained more than 50 million MYR in revenue through the service. AirAsia also reported that $40 \%$ of sales is from the Internet, with the remainder coming from the other channels. In comparison, other low cost airlines have higher percentages for sales through the Internet. Ryanair, easyJet and VirginBlue each has the Internet sales percentages of $94 \%, 90 \%$ and $70 \%$ respectively (Saywell and Neuman 2003). Another advantage of AirAsia's use of electronic commerce is that customers from other parts of the world are able to use the airline services as noted by Tony Fernandes, the CEO about passengers from the US and UK, who did their bookings on the Internet (Devasahayam, 2003).

\section{CONCLUSION}

We can learn a couple of important lessons from the case studies above. Firstly, electronic commerce acceptance and usage is still not far reaching although the possibilities of electronic commerce can be far reaching. As we can see, electronic commerce is slowly catching on in developing and less developed countries, resulting in from lower numbers of Internet users as well as attitude towards fraud and security concerns. The situation is different in more developed countries, where electronic commerce is widely accepted and used.

The disparity between developed and developing and less developed countries can be seen in Table 1, which shows worldwide electronic commerce growth from 2000 to 2004. Despite the growing amounts of electronic commerce, outside of the developed countries (US, Japan, Western Europe, Canada and Australia), the growth of electronic commerce is minimal. For example, growth in Latin America and the rest of the world (including Africa and Eastern Europe) is expected to increase from 6.8 million USD in 2000 to 150.4 million USD in 2004. These figures represent about one per cent of worldwide electronic commerce sales. Some countries will rapidly move towards to embrace more and more electronic commerce, while some countries will lag behind. Until electronic commerce become widely accessible and accepted worldwide, the role of traditional marketing or distribution channels will remain. Massive disintermediation or reintermediation has not happened as expected by optimists when electronic commerce started to take hold. Gallaugher (2002) stated "The extent of the collapse of distribution channels brought about by the advent of the Internet appears to have been over estimated."

The second lesson we can learn from the case studies is the nature of products or services offered on-line plays an important role in the success of electronic commerce. Not every product or service is suitable for the marketspace. Many writers and researches have pointed out the importance of product characteristics (Peterson, 
Balasubramanian and Bronnenberg, 1997; Kiang, Raghu and Shang, 2000 and Gallaugher, 2002). Peterson, Balasubramanian and Bronnenberg (1997: 335-336) proposed that products and services considered for electronic commerce must be examined based on the following dimensions:

- $\quad$ Cost and frequency of purchase: Are the products or services low-cost and frequently purchased or high-cost and infrequently purchased? In general, when purchase requires physical delivery, the more frequent the purchase and the smaller the cost (for example consumable product like milk), the less likely there is to be a good "fit" between a product or service and the Internet. High-cost and infrequently purchased goods may be more suitable for the Internet.

- Value proposition: Are the products or services tangible and physical or intangible and service-related? To the extent that the value proposition is intangible, the greater the frequency of purchase or use of a good, the greater the advantage of the Internet as a transaction and distribution medium.

- Degree of differentiation: To what degree is a product or service differentiable? When products or services are capable of significant differentiation, the Internet can serve as an effective segmentation mechanism for guiding buyers to their ideal product or service.

Kiang, Raghu and Shang (2000) confirmed Peterson, Balasubramanian and Bronnenberg's proposition.

In Maybank's and AirAsia's case studies, we can conclude that because the products or services offered by both organizations fit in the second dimension above, both organizations are able to successfully implement electronic commerce as part of their operations. In the case of AirAsia, a certain degree of differentiation from its competitors also contributed to its success in electronic commerce. Products, which are intangible and service-related are more likely to contribute to success in electronic commerce.

With respect to distribution channels, we have seen that the implementation of electronic commerce in both Maybank and AirAsia has not affected traditional distribution channels. Both organizations complemented its preInternet channels with its Internet banking services. In AirAsia's case, the airline was able to extend its sales beyond Malaysia.

In summary, while the Internet has presented additional functionalities and opportunities for the marketing function, it has only become a new medium to overcome the problem of physical separation between sellers and buyers. Decisions on marketing or distribution channels in times to come will continue to be based on the constructs developed previously. However, additional considerations have to be made for the use of the Internet as another option in the marketing or distribution channel.

\section{References}

1. Abd.Mukti, N. (2000) Barriers to Putting Businesses on the Internet in Malaysia. The Electronic Journal on Information Systems in Developing Countries, Vol.2, No.6, pp.1-6. http://www.is.cityu.edu.hk/ research/ejisdc/vol2/v2r6.pdf [Accessed 5 October 2003]

2. Ang, B.L. (2000). Where are the Shoppers? CIO Asia, October http://www.cioasia.com/pcio.nsf/0/5D7154B69989A3C148256B3E0032A812? OpenDocument [Accessed 5 October 2003]

3. Bonne, J. (2002). The airline business doesn't work ... but low-cost, short-haul airlines are changing the equation. MSNBC, 5 December. http://www.msnbc.com/news/843222.asp?cp1=1 [Accessed 5 October 2003]

4. Chaffey, D. (2002). E-business and e-commerce management. Essex: Pearson Education Limited

5. Devasahayam, A. (2003). Have Net will travel. C | Level, January/February 2003. http://www.trinetizen.com/ Accessed 5 October 2003]

6. Gallaugher, J.M. (2002). E-Commerce and the undulating distribution channel, Communications of the Association for Computing Machinery, Vol. 45, No. 7.

7. Hoffman, D.L, T.P. Novak, and P. Chatterjee (1995). Commercial scenarios for the web: opportunities and challenges. Journal of Computer-Mediated Communication, Special Issue on Electronic Commerce, Vol.1, No.3. http://www.ascusc.org/jcmc/voll/issue3/hoofman.html/ [Accessed 5 October 2003] 
8. Kalakota, R. and A.B. Whinston (1997). Electronic commerce - a manager's guide. Reading, MA: AddisonWesley Longman, Inc.

9. Kiang, M.Y, T.S. Raghu, and K.H. Shang (2000) Marketing on the Internet - who can benefit from an online marketing approach? Decision Support Systems, No. 27, pp.383-393

10. Kotler, P. (2000). Marketing management - millennium edition. Upper Saddle River, N.J. : Prentice Hall

11. Lambin, J. (2000). Market-driven management - strategic and operational marketing. London: Macmillan Press Ltd

12. Malaysian Communications and Multimedia Commission (2003). MCMC | facts \& figures | statistics \& records. http://www.mcmc.gov.my/mcmc/facts_figures/stats/index.asp [Accessed 5 October 2003]

13. Mallen, B.E. (1967). The marketing channel - a conceptual viewpoint. New York: John Wiley \& Sons Inc.

14. Peterson, R.A, S. Balasubramanian, and B.J. Bronnenberg (1997). Exploring the implications of the Internet for consumer marketing Journal of the Academy of Marketing Science. Vol.25, Iss.4; pp.329-347.

15. Saywell, T and S. Neuman (2003). No frills, small bills. Far Eastern Economic Review, Vol.166, Iss.166, 16 July, p.32

16. Sheth, J.N. and R. S. Sisodia (1999). Revisiting marketing's lawlike generalizations. Journal of the Academy of Marketing Science, Vol.27, No.1, pp-71-87.

17. Utusan Malaysia (2003). Maybank confident more corporations will use its maybank2U.com. Utusan Malaysia, 11 October. http://www.utusan.com.my/utusan/archive.asp?y=2003\&dt=1011\&pub =utusan_express\&sec $=$ corporate\&pg=co_07.htm\&arc=hive [Accessed 15 October 2003]

18. Wigand, R.T. (1997) Electronic commerce: definition, theory, and context. The Information Society, Vol. 13, No. 1. pp.1-16.

\section{Appendix}

Figure 1: Channel Levels

\section{CONSUMER MARKETING LEVELS}

\section{ZERO-LEVEL}

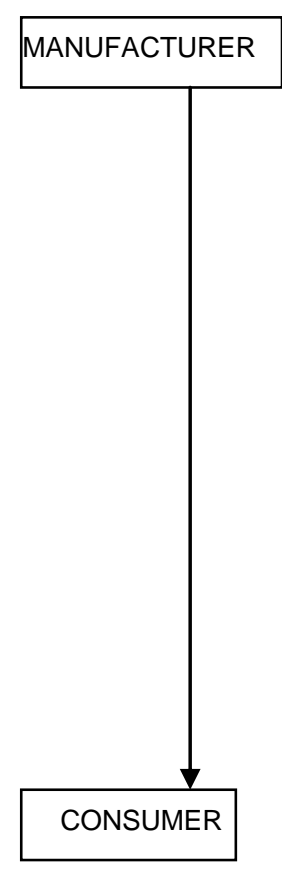

ONE-LEVEL

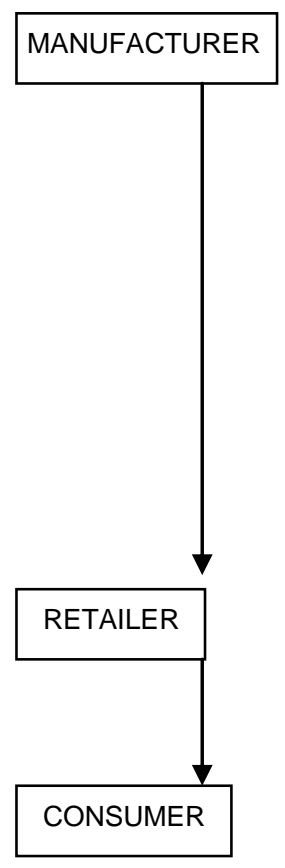

TWO-LEVEL

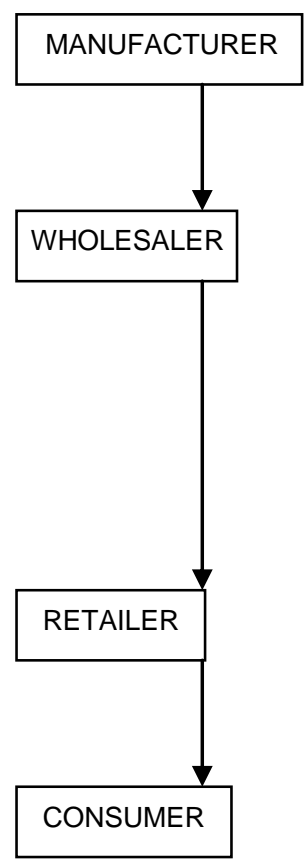

THREE-LEVEL

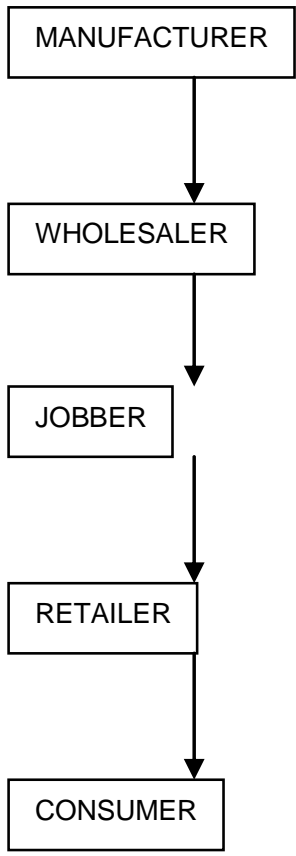

Source: Kotler (2000: 493) 
Table 1: Worldwide electronic commerce growth (2000-2004)

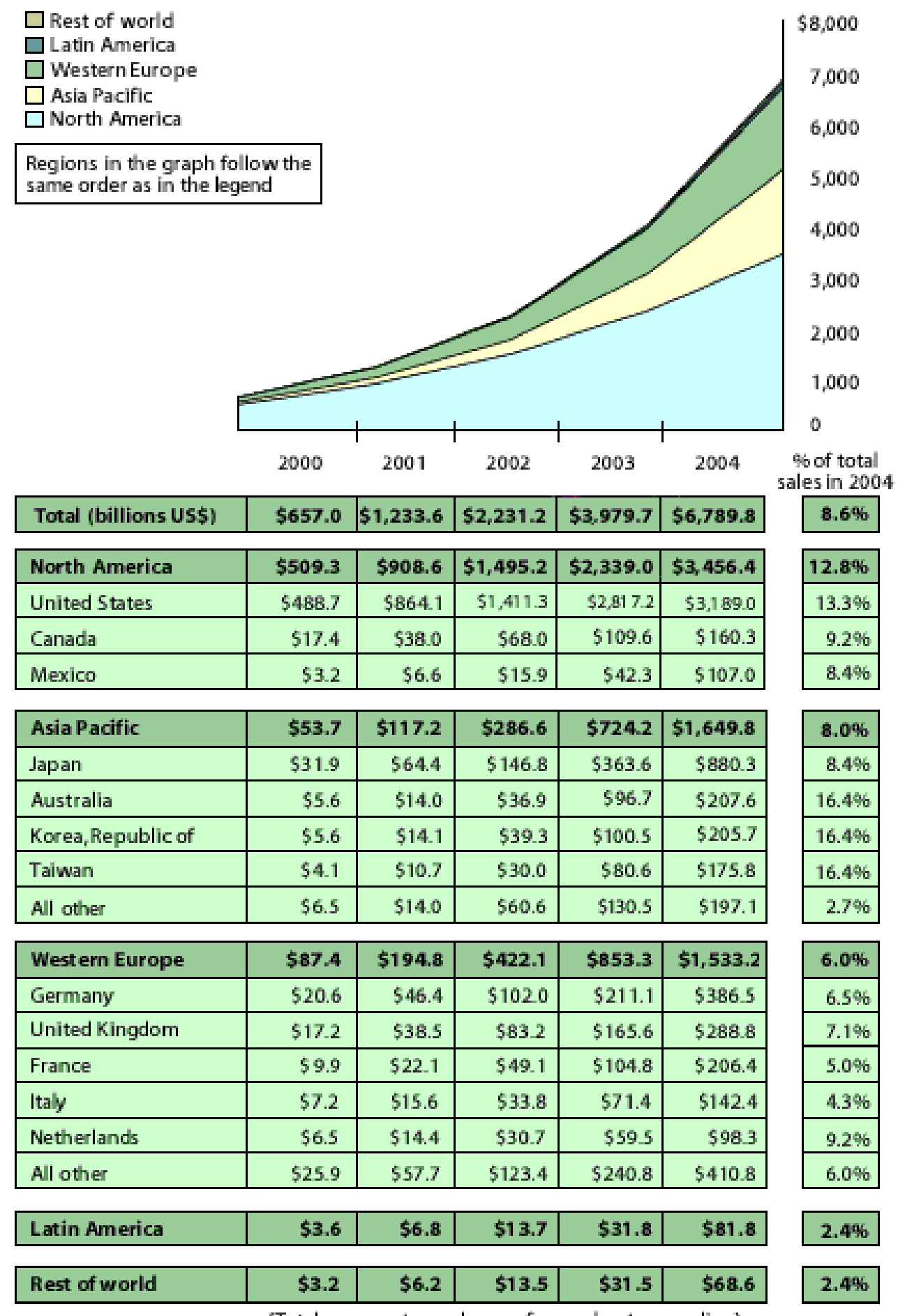

Source: Forrester Research (2000 in Chaffey, 2002: 13) 
Table 2: Internet Users in Malaysia (1995-2003)

\begin{tabular}{|c|c|}
\hline Year & No of Users (thousands) \\
\hline 1995 & 42 \\
\hline 1996 & 192 \\
\hline 1997 & 615 \\
\hline 1998 & 1,215 \\
\hline 1999 & 2,004 \\
\hline 2000 & 4,977 \\
\hline 2001 & 6,345 \\
\hline 2002 & 7,842 \\
\hline 2003 & 8,187 \\
\hline
\end{tabular}

Source: Malaysian Communications and Multimedia Commission (2003)

\section{NOTES}


NOTES 